\title{
Corrigendum to "A Wearable Robotic Device Based on Twisted String Actuation for Rehabilitation and Assistive Applications"
}

\author{
Mohssen Hosseini, Roberto Meattini, Gianluca Palli, and Claudio Melchiorri \\ Università di Bologna (DEI), Viale Risorgimento 2, Bologna, Italy \\ Correspondence should be addressed to Gianluca Palli; gianluca.palli@unibo.it \\ Received 8 August 2017; Accepted 7 September 2017; Published 20 September 2017
}

Copyright (C) 2017 Mohssen Hosseini et al. This is an open access article distributed under the Creative Commons Attribution License, which permits unrestricted use, distribution, and reproduction in any medium, provided the original work is properly cited.

\begin{abstract}
In the article titled "A Wearable Robotic Device Based on Twisted String Actuation for Rehabilitation and Assistive Applications" [1], in the "4.2. TSA Design Validation" section, the text reading "The maximum deformation with the maximum load of $80 \mathrm{~N}$ is $\Delta X_{\max } \simeq 1.08 \cdot 10^{-4} \mathrm{~m}$ indicating the compliant frame deformation is within the goal working region $\Delta d<0.12 \mathrm{~mm}$ and can be considered linear." should be corrected as follows.

"The maximum deformation with the maximum load of $80 \mathrm{~N}$ is $\Delta X_{\max } \simeq 2.34 \cdot 10^{-4} \mathrm{~m}$ indicating the compliant frame deformation is within the goal working region $\Delta d<0.12 \mathrm{~mm}$ and can be considered linear."
\end{abstract}

\section{References}

[1] M. Hosseini, R. Meattini, G. Palli, and C. Melchiorri, "A wearable robotic device based on twisted string actuation for rehabilitation and assistive applications," Journal of Robotics, vol. 2017, Article ID 3036468, 11 pages, 2017. 


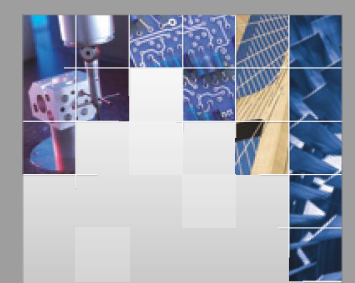

\section{Enfincering}
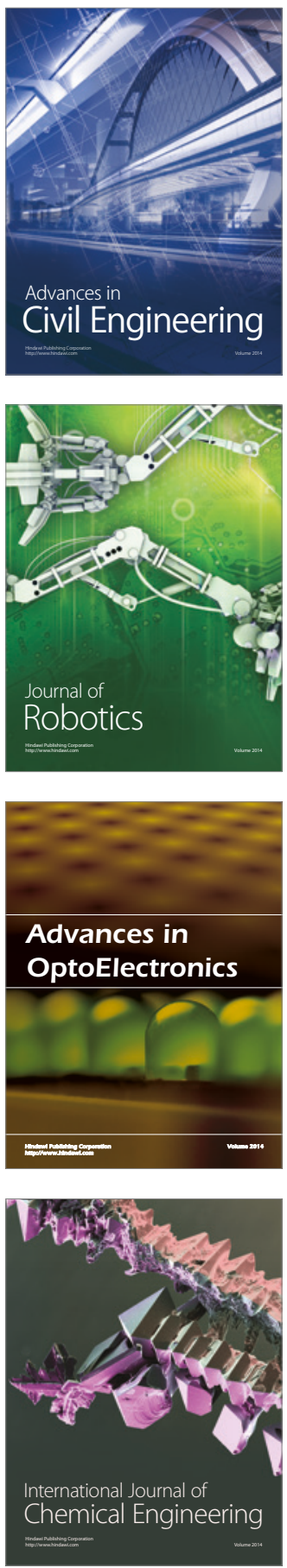

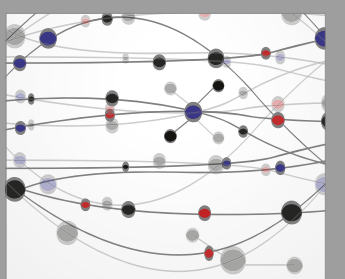

The Scientific World Journal

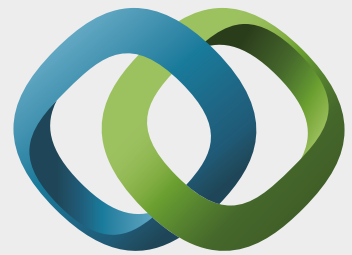

\section{Hindawi}

Submit your manuscripts at

https://www.hindawi.com
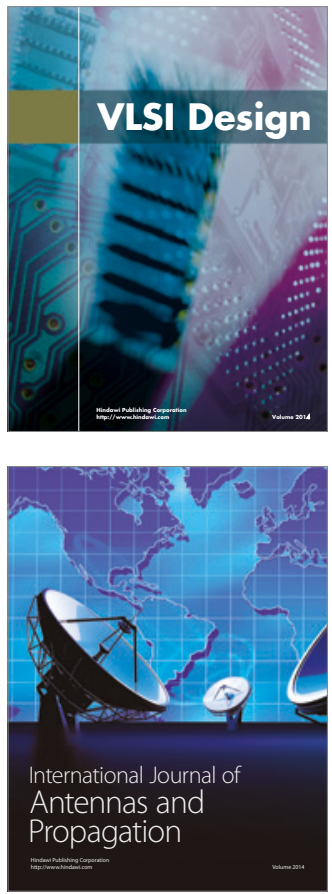

\section{Rotating}

Machinery
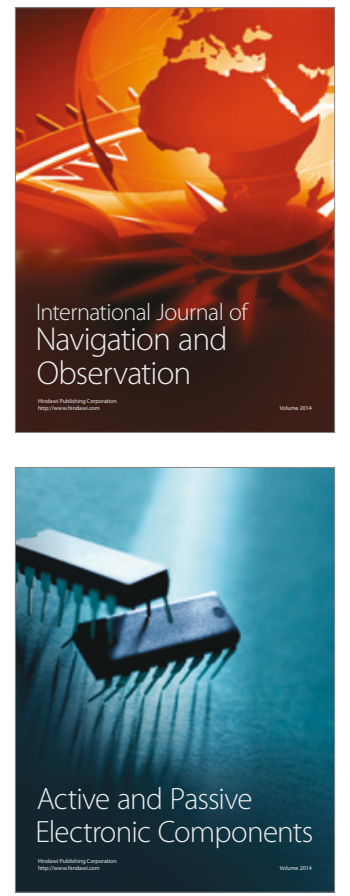
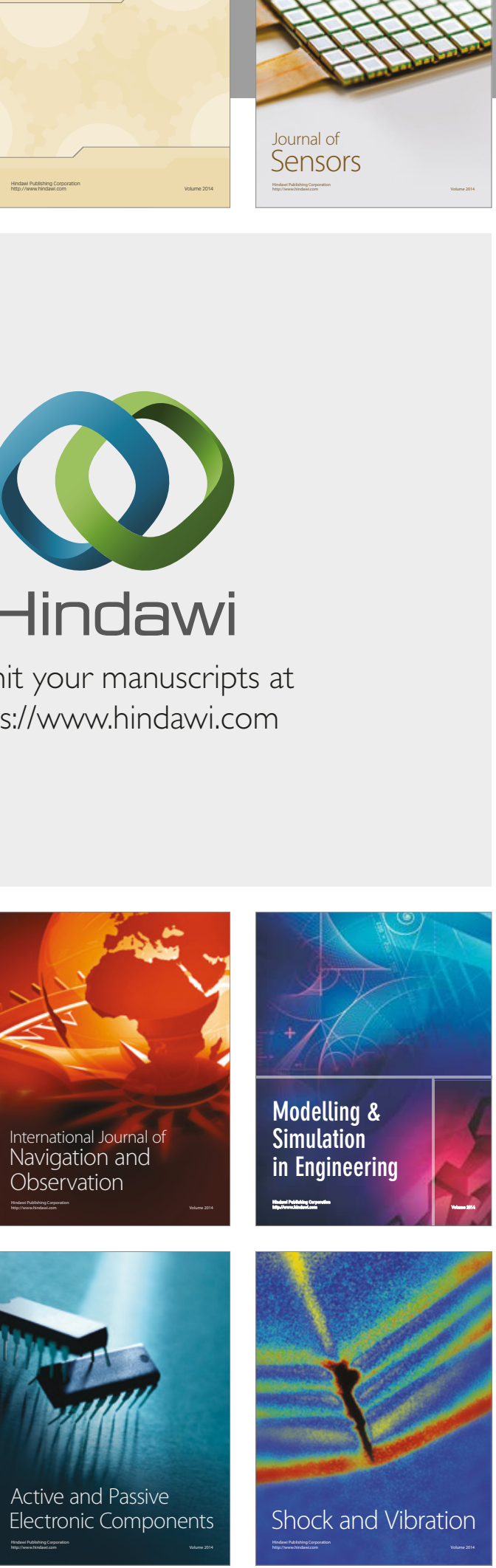
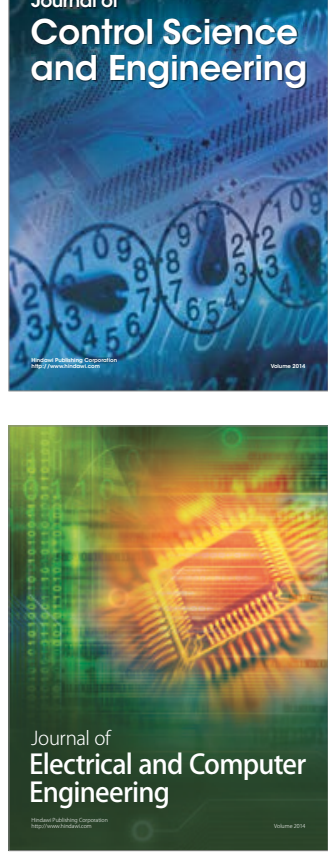

Distributed

Journal of

Control Science

and Engineering
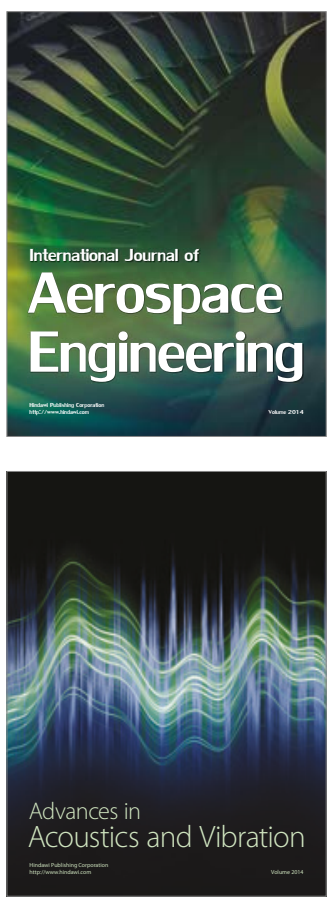

Sensor Networks 